\title{
Primary aldosteronism in Klinefelter's syndrome: two cases
}

\author{
Yasufumi Seki', Satoshi Morimoto', Naohiro Yoshida', Kanako Bokuda', \\ Nobukazu Sasaki', Midori Yatabe'1, Junichi Yatabe1, Daisuke Watanabe', Satoru Morita², \\ Keisuke Hata ${ }^{3}$, Tomoko Yamamoto4, Yoji Nagashima ${ }^{4}$ and Atsuhiro Ichihara1
}

Departments of ${ }^{1}$ Endocrinology and Hypertension, ${ }^{2}$ Diagnostic Imaging and Nuclear Medicine, 3 Urology, Kidney Center, and ${ }^{4}$ Surgical Pathology, Tokyo Women's Medical University, Tokyo, Japan

\author{
Correspondence \\ should be addressed \\ to S Morimoto \\ Email \\ morimoto.satoshi@twmu. \\ ac.jp
}

\section{Summary}

Primary aldosteronism (PA) is more common than expected. Aberrant adrenal expression of luteinizing hormone (LH) receptor in patients with PA has been reported; however, its physiological role on the development of PA is still unknown. Herein, we report two unique cases of PA in patients with untreated Klinefelter's syndrome, characterized as increased serum LH, suggesting a possible contribution of the syndrome to PA development. Case 1 was a 39-year-old man with obesity and hypertension since his 20s. His plasma aldosterone concentration (PAC) and renin activity (PRA) were 220 $\mathrm{pg} / \mathrm{mL}$ and $0.4 \mathrm{ng} / \mathrm{mL} / \mathrm{h}$, respectively. He was diagnosed as having bilateral PA by confirmatory tests and adrenal venous sampling (AVS). Klinefelter's syndrome was suspected as he showed gynecomastia and small testes, and it was confirmed on the basis of a low serum total testosterone level ( $57.3 \mathrm{ng} / \mathrm{dL})$, high serum LH level $(50.9 \mathrm{mlU} / \mathrm{mL})$, and chromosome analysis. Case 2 was a 28-year-old man who had untreated Klinefelter's syndrome diagnosed in his childhood and a 2-year history of hypertension and hypokalemia. PAC and PRA were $247 \mathrm{pg} / \mathrm{mL}$ and $0.3 \mathrm{ng} / \mathrm{mL} / \mathrm{h}$, respectively. He was diagnosed as having a $10 \mathrm{~mm}$-sized aldosterone-producing adenoma (APA) by AVS. In the APA, immunohistochemical analysis showed co-expression of LH receptor and CYP11B2. Our cases of untreated Klinefelter's syndrome complicated with PA suggest that increased serum LH levels and adipose tissues, caused by primary hypogonadism, could contribute to PA development. The possible complication of PA in hypertensive patients with Klinefelter's syndrome should be carefully considered.

\section{Learning points:}

- The pathogenesis of primary aldosteronism is still unclear.

- Expression of luteinizing hormone receptor has been reported in aldosterone-producing adenoma.

- Serum luteinizing hormone, which is increased in patients with Klinefelter's syndrome, might contribute to the development of primary aldosteronism.

\section{Background}

Primary aldosteronism (PA) is more common than was expected: $5-10 \%$ of hypertensive patients are reported to have the condition (1). Because specific treatments, including adrenalectomy and mineralocorticoid receptor antagonist treatment, can reduce cardiovascular event risks in patients with PA, careful screening and appropriate diagnosis are recommended to improve their prognosis (1).

Pathophysiology of aldosterone hypersecretion in PA has been partially explained by aberrant adrenal expression of some hormone receptors. Aberrant adrenal expression of luteinizing hormone ( $\mathrm{LH})$ receptor has been 
reported in aldosterone-producing adenoma (APA) (2). It has also been reported that LH increased aldosterone secretion of APA in an in vitro study (3). In some patients with PA, response of aldosterone to $\mathrm{LH}$ administration were also reported (4). However, the physiological role of LH receptor in adrenal aldosterone secretion in patients with PA has been still unknown.

Klinefelter's syndrome is a common cause of male primary hypogonadism, which is characterized as increased serum LH level. Herein, we report two unique cases of patients with Klinefelter's syndrome complicated by PA, suggesting a possible contribution of Klinefelter's syndrome in the PA development.

\section{Case presentation}

\section{Case 1}

A 39-year-old man was referred to our hospital for a closer inspection of hypertension with adrenal incidentaloma. He had been diagnosed with hypertension and diabetes in his 20s but had stopped visiting his doctors thereafter. He underwent computed tomography (CT) because of headache and stomachache, and an adrenal tumor was discovered. His medical history was remarkable for surgery for patent ductus arteriosus.

\section{Case 2}

A 28-year-old man was referred to our hospital because of hypertension. He had a 2-year history of hypertension and received $10 \mathrm{mg}$ of amlodipine, $4 \mathrm{mg}$ of doxazosin and $10 \mathrm{mg}$ of furosemide. He had also been diagnosed as having Klinefelter's syndrome during childhood, and chromosome analysis revealed a mosaic of $47, \mathrm{XXY}$, and 48 , XXY, +18. His medical history was remarkable for ventricular septal defect and ulcerative colitis.

\section{Investigation}

\section{Case 1}

This man's height was $159 \mathrm{~cm}$ and BMI was $35.2 \mathrm{~kg} / \mathrm{m}^{2}$. He had mild gynecomastia. His blood pressure was $128 / 79 \mathrm{mmHg}$ with $60 \mathrm{mg}$ nifedipine. Laboratory findings were as follows: potassium, $4.2 \mathrm{mEq} / \mathrm{L}$; plasma aldosterone concentration (PAC), $220 \mathrm{pg} / \mathrm{mL}$; and plasma renin activity (PRA), $0.4 \mathrm{ng} / \mathrm{mL} / \mathrm{h}$. He was diagnosed as having PA according to an aldosterone-renin ratio (ARR) of 240 after the captopril challenge test (CCT) and a PRA of $1.4 \mathrm{ng} / \mathrm{mL} / \mathrm{h}$ after the furosemide upright test (Table 1 ), per the guideline of the Japanese Society of Hypertension (5). Abdominal CT revealed a 10-mm-sized left adrenal adenoma (Fig. 1A). His plasma cortisol level was suppressed to $0.8 \mu \mathrm{g} / \mathrm{dL}$ after the 1-mg dexamethasone suppression test. Adrenal venous sampling (AVS) after cosyntropin injection revealed a low lateralized ratio (LR) of 1.2 and high contralateral ratio (CR) of 2.0, indicating bilateral PA, per the Endocrine Society guidelines (1), which suggested idiopathic hyperaldosteronism (IHA) with non-functioning adenoma (Table 2). During the AVS, his small testes were incidentally identified, but he refused further investigation at the time. At the age of 43 years, he agreed to receive gonadal survey, which revealed a low serum total testosterone level $(57.3 \mathrm{ng} / \mathrm{dL}$; normal range: $284-799 \mathrm{ng} / \mathrm{dL})$, high LH level $(50.9 \mathrm{mIU} / \mathrm{mL}$; normal range: $1.7-11.2 \mathrm{mIU} / \mathrm{mL}$ ) and high FSH level (68.2 $\mathrm{mIU} / \mathrm{mL}$; normal range: 2.1-18.6 $\mathrm{mIU} / \mathrm{mL}$ ). Chromosome analysis revealed 47, XXY, and he was diagnosed as having Klinefelter's syndrome.

\section{Case 2}

His height was $164.8 \mathrm{~cm}$ and BMI was $22.6 \mathrm{~kg} / \mathrm{m}^{2}$. Blood pressure was 131/86 mmHg. He had mild gynecomastia. Laboratory findings were as follows: potassium, $3.3 \mathrm{mEq} / \mathrm{L}$; PAC, $247 \mathrm{pg} / \mathrm{mL}$; PRA, $0.3 \mathrm{ng} / \mathrm{mL} / \mathrm{h}$; serum total testosterone, $182.2 \mathrm{ng} / \mathrm{dL}$; serum $\mathrm{LH}, 29.5 \mathrm{mIU} / \mathrm{mL}$; and serum $\mathrm{FSH}, 36.3 \mathrm{mIU} / \mathrm{mL}$. He was diagnosed as PA because ARR after CCT was 245 and PAC after saline infusion test was $204 \mathrm{pg} / \mathrm{mL}$ (Table 1), according to the guideline (5). Abdominal CT revealed a $10 \mathrm{~mm}$-sized right adrenal adenoma (Fig. 1B). The AVS revealed that LR was 3.5 and CR was 1.0 (Table 2).

\section{Treatment}

\section{Case 1}

He started taking eplerenone after bilateral PA was confirmed by the AVS. He also started to receive testosterone enanthate replacement therapy at the time.

\section{Case 2}

Considering his age, hypokalemia, unilateral right adrenal tumor and tendency of right-sided higher aldosterone secretion confirmed by AVS, he received right laparoscopic adrenalectomy, which improved his hypokalemia and hypertension. The resected tumor was pathologically 
Table 1 Confirmation tests to diagnose primary aldosteronism in the present cases.

\begin{tabular}{l}
\hline \\
\hline Captopril challenge test \\
Time \\
PAC, pg/mL \\
PRA, ng/mL/h \\
ARR \\
Furosemide upright test \\
Time \\
PAC, pg/mL \\
PRA, ng/mL/h \\
Saline infusion test \\
Time \\
PAC, pg/mL \\
PRA, ng/mL/h
\end{tabular}

\begin{tabular}{c}
\hline \\
Baseline \\
187 \\
0.5 \\
374 \\
Baseline \\
101 \\
0.4 \\
Baseline \\
226 \\
0.6
\end{tabular}

Case 1

$\begin{array}{cc}60 \min & 90 \min \\ 102 & 120 \\ 0.5 & 0.7 \\ 204^{*} & 240^{\star}\end{array}$

$60 \mathrm{~min}$

432

1.2

$120 \min$
47.9
0.3

$120 \min$
551
$1.4^{*}$

$240 \mathrm{~min}$

102

0.4

\begin{tabular}{c}
\hline \\
Baseline \\
236 \\
0.6 \\
393 \\
Baseline \\
278 \\
0.9 \\
Baseline \\
304 \\
0.6 \\
\hline
\end{tabular}

Case 2

$\begin{array}{cc}60 \min & 90 \min \\ 196 & 176 \\ 0.8 & 0.9 \\ 245^{\star} & 196\end{array}$

$60 \mathrm{~min}$

340

3.6

$120 \min$

311

4.8

$120 \min$
190
0.3

$240 \mathrm{~min}$

$204^{*}$

0.3

Asterisks represent positive results according to the guidelines of the Japanese Society of Hypertension (5).

ARR, aldosterone-renin ratio; PAC, plasma aldosterone concentration; PRA, plasma renin activity.

diagnosed as APA, as it included mainly clear cells (Fig. 1C) with positive CYP11B2 immunostaining using antiCYP11B2 antibodies (obtained by the courtesy of Dr. K Nishimoto, Department of Uro-Oncology, Saitama Medical University International Medical Center, Japan) (Fig. 1D). Remarkably, triple-label immunofluorescence analysis for nuclei, CYP11B2, and LH receptor using 4', 6-diamidino-2-phenylindole (40043, Biotium, Fremont, CA, USA) and anti-CYP11B2 and anti-LH/hCG receptor antibodies (SAB2700732, Sigma-Aldrich), respectively, revealed co-expression of CYP11B2 and LH receptor in the cytosol of some tumor cells (Fig. 2). He started to receive testosterone enanthate supplementation therapy 2 years after the surgery.

\section{Outcome and follow-up}

\section{Case 1}

Blood pressure was not affected by the testosterone supplementation therapy and was maintained under taking $100 \mathrm{mg}$ of eplerenone, $40 \mathrm{mg}$ of nifedipine, $5 \mathrm{mg}$ of amlodipine, and $40 \mathrm{mg}$ of telmisartan 3 years after the AVS.

\section{Case 2}

Soon after the adrenalectomy, hypokalemia and high blood pressure was improved. Six months after the surgery, his blood pressure was maintained under taking $10 \mathrm{mg}$ of furosemide and $2.5 \mathrm{mg}$ of amlodipine and plasma renin
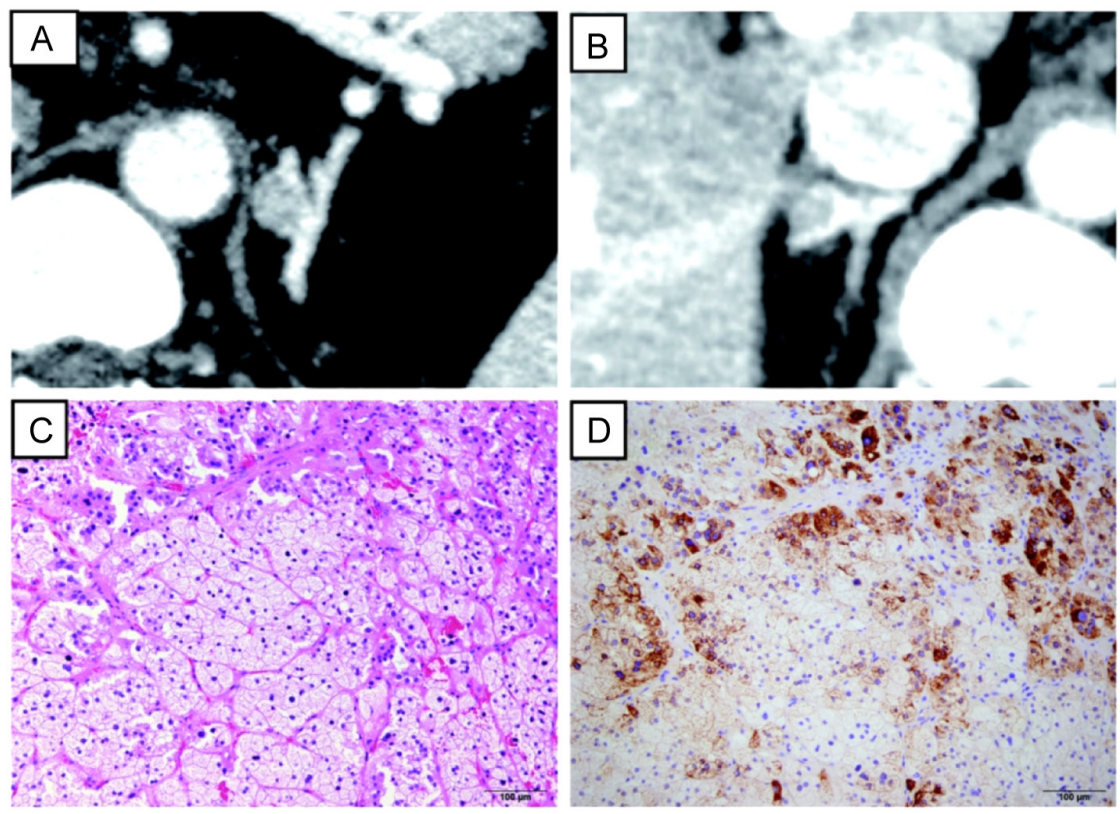

Figure 1

Radiological findings of the adrenal adenomas of the present cases. (A) A trans-axial contrastenhanced computed tomography (CT) image shows a left adrenal adenoma, $10 \mathrm{~mm}$ in diameter, in case 1. (B) A trans-axial contrastenhanced $\mathrm{CT}$ image shows a right adrenal adenoma, $10 \mathrm{~mm}$ in diameter, in case 2. (C) Hematoxylin-eosin staining for the resected adrenal adenoma of case 2 . The tumor-contained cells with abundant clear cytoplasm and rounded nuclei. (D) Immunohistochemistry for CYP11B2 of the resected adrenal adenoma of case 2 . 
Table 2 Adrenal venous sampling after cosyntropin injection.

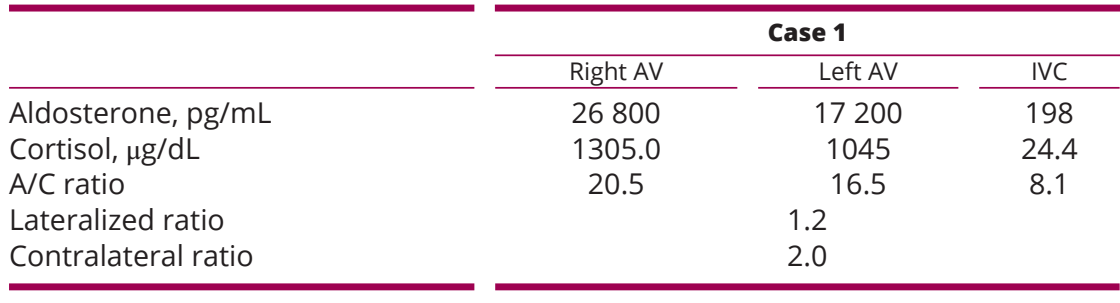

\begin{tabular}{|c|c|c|}
\hline \multicolumn{3}{|c|}{ Case 2} \\
\hline Right AV & Left AV & IVC \\
\hline 36000 & 10100 & 270 \\
\hline 640.2 & 629.8 & 17.0 \\
\hline 56.2 & 16.0 & 15.9 \\
\hline \multicolumn{3}{|c|}{3.5} \\
\hline \multicolumn{3}{|c|}{1.0} \\
\hline
\end{tabular}

Lateralized ratio was defined as the aldosterone-to-cortisol concentration ratio on the higher side of the adrenal glands over the aldosterone-to-cortisol concentration ratio on the lower side. Contralateral ratio was defined as the adrenal aldosterone-to-cortisol concentration ratio on the lower side over the aldosterone-to-cortisol concentration ratio on the inferior vena cava.

$\mathrm{A} / \mathrm{C}$, aldosterone/cortisol; $\mathrm{AV}$, adrenal vein; IVC, inferior vena cava.

activity was increased to $2.3 \mathrm{ng} / \mathrm{mL} / \mathrm{h}$. Two years after the operation, his blood pressure was maintained by taking 10 $\mathrm{mg}$ of amlodipine, $20 \mathrm{mg}$ of cilnidipine, and $100 \mathrm{mg}$ of eplerenone. Thus, the persistent increased blood pressure was thought due to primary hypertension. After testosterone supplementation therapy was started, his blood pressure decreased and 10 months later, amlodipine was stopped.

\section{Discussion}

We present two unique cases of Klinefelter's syndrome with PA. In the resected APA of case 2, interestingly, immunohistochemical analysis revealed co-localized expression of LH receptor and CYP11B2, aldosterone synthase. Both patients had never received testosterone supplementation therapy and had developed hypertension in their 20s. We propose two possible mechanisms by which Klinefelter's syndrome could contribute to PA development.

First, increased serum LH levels due to Klinefelter's syndrome could contribute to PA development. Typically, serum LH levels are increased in patients with primary hypogonadism in adulthood. Also, experimental studies on orchiectomized rats show increased PAC (6). Moreover, it was also reported that the $\mathrm{LH}$ receptor was expressed in APA and LH-stimulated aldosterone production in primary cultures from APA (3). Here, we observed co-expression of $\mathrm{LH}$ receptor and CYP11B2 in the APA of case 2. In this scenario, increased serum LH levels since adolescence might stimulate aldosterone secretion and contribute to PA development. Of note, in postmenopausal women, serum LH is negatively correlated with urinary aldosterone excretion (7). The effects of the hormone on PA development might be observed only in men. A recent study showed that cytosolic expression of $\mathrm{LH}$ receptor in APAs and non-functioning adrenal carcinoma suggesting that cytosolic LH receptor expression might represent the alteration of its function (8). Further study is needed to solve these limitations and suggest this hypothesis.

Another possible contributor to aldosterone excess might be increased adipose tissue caused by hypogonadism. In fact, obesity was observed in $42.6 \%$ of patients with Klinefelter's syndrome in their adulthood (9). Also, obesity is common in IHA, and it has been hypothesized that it increases aldosterone secretion through hyperproduction of adipocytokines (10). In case 1 we show IHA with obesity; thus, not only increased serum LH but also increased adipose tissues could affect the PA development.

Our cases suggest that patients with untreated Klinefelter's syndrome might be complicated by PA in adulthood. Indeed, prevalence of hypertension was reported
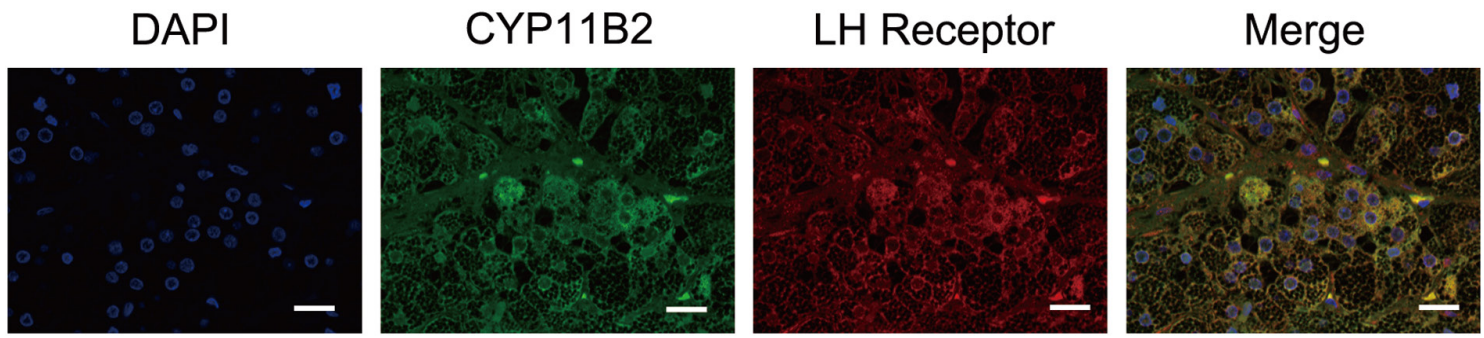

\section{Figure 2}

Co-expression of CYP11B2 and LH receptor in the aldosterone-producing adenoma of case 2. Subcellular localization of nuclei, CYP11B2 and LH receptor of the resected aldosterone-producing adenoma of the case 2 were determined by triple-label immunofluorescence using 4 ',6-diamidino-2-phenylindole (DAPI), anti-CYP11B2 antibody and anti-LH/hCG receptor antibody, respectively. Merge shows combined images for DAPI (blue), CYP11B2 (green), and LH receptor (blue). Scale bars represent $20 \mu \mathrm{m}$. 
as $12.5 \%$ in non-obese and $18.8 \%$ in obese patients with untreated Klinefelter's syndrome (9). Coexistence of PA and this syndrome has rarely been reported, except for a case of aldosterone-secreting adrenal carcinoma (11); hence, the prevalence of PA in patients with Klinefelter's syndrome is still unclear. Considering our cases, it is possible that, at least, a fraction of untreated Klinefelter's patients also have PA. The fact that patients with both conditions have rarely been reported might be explained by the underdiagnoses of the two diseases, although the possibility of coincidence of these two conditions cannot be ruled out. Because testosterone supplementation therapies can decrease serum LH levels, adipose tissue mass, and possibly PAC in patients with Klinefelter's syndrome, those therapies might contribute to masking underlying PA, or prevention from developing PA. In case 2, blood pressure decreased after the testosterone supplementation therapy. The supplementation might have decreased LH-dependent aldosterone secretion of the residual adrenal gland and have improved the persistent hypertension after the adrenalectomy. Further study is needed for an effect of testosterone supplementation on blood pressure in Klinefelter's syndrome.

In conclusion, our cases of concomitant untreated Klinefelter's syndrome and PA suggest that increased serum LH levels and adipose tissues due to Klinefelter's syndrome could contribute to PA development, although the complication of the two diseases might represent a coincidence. Thus, the possible complication of PA in hypertensive patients with Klinefelter's syndrome should be carefully considered.

\section{Declaration of interest}

The authors declare that there is no conflict of interest that could be perceived as prejudicing the impartiality of this case report.

\section{Funding}

This research did not receive any specific grant from any funding agency in the public, commercial or not-for-profit sector.

\section{Patient consent}

Written informed consent has been obtained from the patients for publication of the case report and accompanying images.

\section{Author contribution statement}

Y S, S M, N Y, K B, N S, M Y, J Y, D W and A I were endocrinologists who involved in the clinical care of the patients. $\mathrm{S} M$ performed the adrenal venous sampling for the patients. $\mathrm{K} \mathrm{S}$ was involved for the adrenalectomy of case 2. TY and $\mathrm{Y} N$ performed the pathological examination.

\section{Acknowledgements}

The authors would like to thank K Nishimoto for providing the CYP11B2 antibody and $\mathrm{N}$ Morishima for her aid in immunohistochemistry. They used instruments of the Medical Research Institute, Tokyo Women's Medical University.

\section{References}

1 Funder JW, Carey RM, Mantero F, Murad MH, Reincke M, Shibata H, Stowasser M \& Young WF. The management of primary aldosteronism: case detection, diagnosis, and treatment: an Endocrine Society clinical practice guideline. Journal of Clinical Endocrinology and Metabolism 2016101 1889-1916. (https://doi. org/10.1210/jc.2015-4061)

2 Saner-Amigh K, Mayhew BA, Mantero F, Schiavi F, White PC, Rao CV $\&$ Rainey WE. Elevated expression of luteinizing hormone receptor in aldosterone-producing adenomas. Journal of Clinical Endocrinology and Metabolism 200691 1136-1142. (https://doi.org/10.1210/jc.2005-1298)

3 Nicolini G, Balzan S, Morelli L, Iacconi P, Sabatino L, Ripoli A \& Fommei E. LH, progesterone, and TSH can stimulate aldosterone in vitro: a study on normal adrenal cortex and aldosterone producing adenoma. Hormone and Metabolic Research 201446 318-321. (https:// doi.org/10.1055/s-0033-1358733)

4 Gagnon N, Cáceres-Gorriti KY, Corbeil G, El Ghoyareb N, Ludwig N, Latour M, Lacroix A \& Bourdeau I. Genetic characterization of GnRH/LH-responsive primary aldosteronism. Journal of Clinical Endocrinology and Metabolism 2018103 2926-2935. (https://doi. org/10.1210/jc.2018-00087)

5 Shimamoto K, Ando K, Fujita T, Hasebe N, Higaki J, Horiuchi M, Imai Y, Imaizumi T, Ishimitsu T, Ito $\mathrm{M}$, et al. The Japanese Society of Hypertension guidelines for the management of hypertension (JSH 2014). Hypertension Research 201437 253-390. (https://doi. org/10.1038/hr.2014.20)

6 Kau MM, Lo MJ, Wang SW, Tsai SC, Chen JJ, Chiao YC, Yeh JY, Lin H, Yau Chik Shum AY, Fang VS, et al. Inhibition of aldosterone production by testosterone in male rats. Metabolism: Clinical and Experimental 199948 1108-1114. (https://doi.org/10.1016/s00260495(99)90123-3)

7 Saxena AR \& Seely EW. Luteinizing hormone correlates with adrenal function in postmenopausal women. Menopause 201219 1280-1283. (https://doi.org/10.1097/gme.0b013e31825540c4)

8 Korol P, Jaranowska M \& Pawlikowski M. Immunohistochemical demonstration of LH/CG receptors in non-neoplastic human adrenal cortex and adrenocortical tumors. Folia Histochemica and Cytobiologica 201957 23-27. (https://doi.org/10.5603/FHC. a2019.0003)

9 Han SJ, Kim KS, Kim W, Kim JH, Lee YH, Nam JS, Seo JA, Kim BK, Lee J, Chung JO, et al. Obesity and hyperglycemia in Korean men with Klinefelter syndrome: the Korean Endocrine Society Registry. Endocrinology and Metabolism 201631 598-603. (https://doi. org/10.3803/EnM.2016.31.4.598)

10 Ohno Y, Sone M, Inagaki N, Yamasaki T, Ogawa O, Takeda Y, Kurihara I, Umakoshi H, Ichijo T, Katabami T, et al. Obesity as a key factor underlying idiopathic hyperaldosteronism. Journal of Clinical Endocrinology and Metabolism 2018103 4456-4464. (https://doi. org/10.1210/jc.2018-00866)

11 Pascual J, Liano F, Garcia-Villanueva A, Salvador JL, Herrero JA \& Ortuno J. Isolated primary aldosteronism in a patient with adrenal carcinoma and XY/XXY mosaic Klinefelter's syndrome. Journal of Urology 1990144 1454-1456. (https://doi.org/10.1016/s0022$5347(17) 39765-3)$

Received in final form 15 November 2019

Accepted 28 November 2019 